\title{
Reconsidering the regional airport network in Norway
}

\author{
Terje Andreas Mathisen • Gisle Solvoll
}

Received: 23 September 2011 / Accepted: 6 December 2011 /Published online: 29 December 2011

(C) The Author(s) 2011. This article is published with open access at SpringerLink.com

\begin{abstract}
Purpose The article addresses how a reduction in the number of regional airports in Norway can improve the air transport services currently characterized by expensive fares, high operating costs and leakage of passengers to larger airports.

Methods Traffic and economic consequences of such structural changes are discussed referring to a case from Northern Norway in which plans exist to replace three regional airports with one larger airport. The welfare consequences are assessed using cost-benefit analysis.

Results The large airport is expected to remove the need for state-subsidized flights (PSO-routes), reduce security upgrade costs, offer passengers lower fares and increase the number of domestic direct flights, as well as being profitable from a welfare perspective.

Conclusions When airports are closed down municipalities must be compensated for the loss of their local airports by building alternative transport infrastructure to make this politically acceptable. It is important to bear in mind that too strong a reduction of the number of airports may weaken parts of the established hub- and spoke system, and could therefore lead to reduced service at existing hubs.
\end{abstract}

Keywords Airport infrastructure - Cost benefit analysis · Regional airports · Regional development · Social efficiency

T. A. Mathisen $(\bowtie) \cdot G$. Solvoll

Bodø Graduate School of Business, University of Nordland,

NO-8049, Bodø, Norway

e-mail: terje.mathisen@uin.no

G. Solvoll

e-mail: gisle.solvoll@uin.no

\section{Introduction}

The importance of airports for regional development has been studied in several countries mainly focusing on economic growth $[1,2]$. It is widely accepted that air transport, despite considerable external costs and possible undesired distributional effects, contributes strongly to economic development e.g. [3], and in particular in the form of catalytic effects [4].

The main argument for constructing the Norwegian regional airports at the end of the 1960's was to establish efficient transport communications between rural towns and airports in the county centres. Today Norway is amongst the countries in Europe with the highest air transport dependency. While Norway in 2003 had a domestic trip rate per capita of 2.27, most European countries had less than one third of this value [5]. Moreover, [5] show that Norway has the highest number of commercial airports with short runways $(<1,000 \mathrm{~m})$ in Europe. To secure appropriate public transport service in the rural areas of Norway, the state purchases flight connections (PSO-routes) between regional airports and to/from their nearest airport with flight connections to/from Oslo Airport, Gardermoen (OSL). Currently, Norway holds nearly $20 \%$ of all restricted Public Service Obligation (PSO) routes in Europe [6]. ${ }^{1}$

Since establishment of these regional airports the Norwegian government has invested substantial resources in upgrading road infrastructure and implementing an effective network of fast craft boat routes along the coast. These investments have reduced travel time between rural towns by car and improved the public transport system. The

$\overline{{ }^{1} \text { For a review }}$ of the PSO-routes in Europe see e.g. [7]. 
reduced travel time by road between airports and requirements for substantial investments to be made at the airports in order to meet international security measures renders some regional airports unprofitable from a welfare perspective. This has revitalised the discussion about the structure of the regional airport network in Norway see e.g. [8]. A question of current interest is therefore whether Norway has too many regional airports with runways shorter than $1,000 \mathrm{~m}$. However, before restructuring the regional airport network can take place, there must be political consensus ensuring that local councils and the county administration agree to structural changes.

The aim of this article is to present the main challenges facing the Norwegian regional airport network and to discuss the consequences for traffic and profitability if scheduled air services are run from fewer and larger airports. In order to discuss the regional implications for Norway and other PSO-countries a case is presented in which three regional airports using solely turboprop planes are replaced by a larger airport capable of serving jet-planes.

The article is structured as follows: Section 2 presents the main challenges for the current Norwegian regional airport structure followed by a suggested way to handle these challenges by reducing the number of airports. This is exemplified in Section 3 by a case of current interest from the regional airport network in Norway. Finally, conclusions and implications are presented in Section 4.

\section{Regional airports in Norway}

\subsection{The airport structure}

The state, through its wholly owned company Avinor, owns and operates 46 airports throughout Norway with a total traffic of about 40 million passengers in 2010 [9]. In addition there are 6 privately owned airports with commercial traffic. The Avinor owned airports are organized into three groups as shown in Fig. 1. The first "group" consists of just the main airport of Norway, Oslo Airport, Gardermoen (OSL). The second group consists of three relatively large airports located near the cities Bergen, Stavanger and Trondheim. Finally, the remaining 42 regional airports are included in the third group. For further details regarding the airport network in Norway see e.g. [10].

\subsection{Challenges for the regional airports in Norway}

Today transport services provided at the regional airports face three major challenges. First, they are characterized by expensive fares and poor flight connections to the capital, Oslo. Second, there are considerable operation deficits and a need for subsidised flights by using the public service obligation system (PSO). Finally, travel surveys show a growing leakage of passengers to larger airports.

\subsubsection{Fare level and route services}

Maximum fares for the regulated regional flights have been adjusted according to the Norwegian Consumer Price Index. Deregulation of the commercial part of the Norwegian air transport market in 1994 resulted in a market situation characterized by [11] as competition with respect to capacity on flights between the large airports. However, the entry into the commercial air transport market of the low cost carrier 'Norwegian Air Shuttle' in 2002 provided increased domestic competition and considerable fare reductions for the main routes. Hence, fares have moved in opposite directions for regulated and commercial flights [10]. Experience from Japan shows similar results with deregulation giving lower fares on high traffic routes and making low traffic routes less competitive - both with respect to fares and service [12].

Only a limited number of the regional airports provide direct connections to the national main airport (OSL). This lack of direct connections makes it difficult for business travellers from rural areas to attend meetings in Oslo without planning an overnight stop. Passengers using the regional air transport services also complain about the disadvantages they face due to relatively low reliability inflicting an extra day's travel with corresponding board and lodging expenses. The above problems have a substantial effect on passengers' generalized travel costs [13].

\subsubsection{Subsidised PSO-operations and airport deficits}

At the time of construction it was decided to establish the regional airports for operation by Short Take-Off and Landing (STOL) planes. Today the STOL-planes impose severe limitations on the number of air transport companies that can participate in the competitive tendering taking place every fourth year [14]. Weak competition for these tendered contracts is well-known in the transport companies, meaning that they can adapt to this market situation by requiring higher subsidies. ${ }^{2}$ The subsidies required for running the PSO-routes have grown during the last years for these flight operations which are characterized by short transport distances and a lack of competition for tendered contracts. In 2010, the state subsidised PSO-operations with about NOK 649 million $^{3}$ involving traffic to and from 29 regional airports. This amount is expected to increase to NOK 693 million in 2011.

\footnotetext{
${ }^{2}$ Game theory literature documents that fewer bidders means reduced competition and reduced welfare for society e.g. [15]

${ }^{3} € 1 \approx$ NOK 8 .
} 
Fig. 1 Airports in Norway owned by Avinor (Source: www.avinor.no)

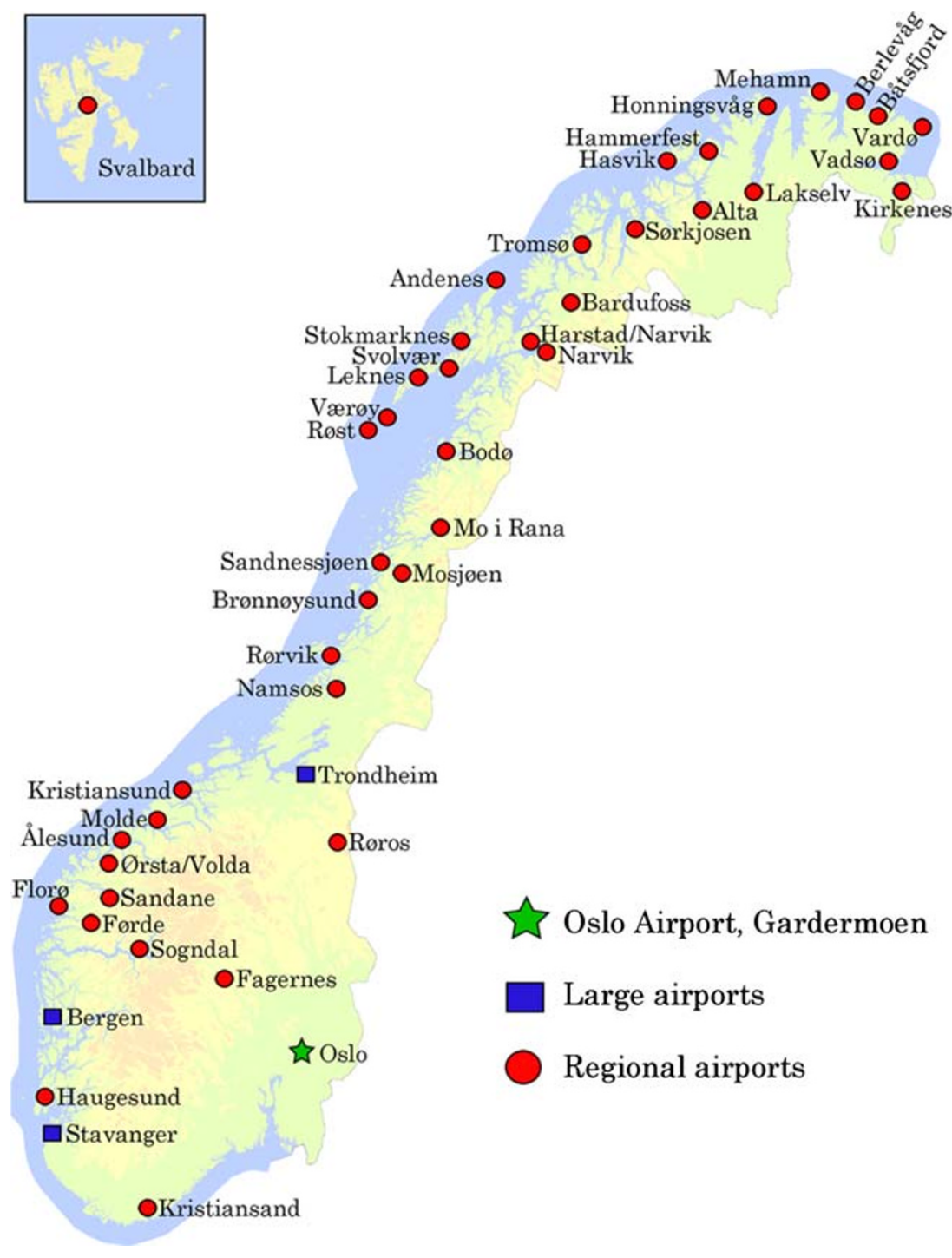

The regional airports had, according to Avinor, an average deficit amounting to about NOK 15.5 million in 2009. In 2006 the Civil Aviation Authority (CAA) issued directives for Norwegian airports aimed at preventing and reducing the extent of accidents in the aviation industry. These regulations (BSL E 3-2) were adopted for regional airports by The Norwegian Ministry of Transport and Communication (MTC) [16]. Avinor estimates that the total investment cost for the regional airports of meeting the new requirements amounts to NOK 1.7 billion.

\subsubsection{Leakage of passengers to larger airports}

In an intra-national "hub and spoke" flight network in which direct flights to the capital are unavailable, demand for transport to the local airport can leak to car transport for the trip to the central airport [17]. Using logistic regression with travel time to airport as an explanatory variable, [8] found that traffic leakages to large airports are commonly found at regional airports in Norway, particularly for leisure trips to the capital or abroad. For example, with 1 h's travel time to the regional airports located north of Trondheim in Fig. 1, only $10 \%$ of the passengers use the local airport while $90 \%$ use the large airport in Trondheim.

Due to high fare level and relatively low frequency, it is reasonable that passengers' travel patterns have gradually shifted to other transport modes than routes to/from the regional airports. This shift in demand is strengthened by the development towards reduced travel time, higher comfort and lower travel costs for intra-region trips using private cars and public sea transport.

\subsection{Are fewer airports the solution?}

The relative increase in service quality for land- and seabased transport compared to air transport indicates that the airport structure is due for revision. Restructuring the regional network into fewer and larger airports could result in 
considerable benefits for both passengers and authorities [8].

The increased number of persons within the catchment area of a joint airport provides increased demand that, together with the availability of long runways, enables carriers to provide better air services - both with respect to quality and frequency. This will, for example, make it more attractive to establish direct connections to large domestic airports. Such direct flights reduce the need for transit and transfer for trips between regional airports and large cities, and will increase traffic due to reduction in passengers' generalized travel costs.

A rearrangement into one airport (one firm with expanded boundaries) will reduce the uncertainty as well as the need for contracts and give reduced transaction costs. ${ }^{4}$ The magnitude of this effect is, however, uncertain since the information mainly flows through the Avinor system which serves both the existing airports to be closed down and the new merged unit. Studies of airport operating costs show the presence of economies of scale e.g. [19]. This indicates that merging of activities by horizontal integration into larger units will be economically viable e.g. [20]. Hence, with fewer sites to operate, Avinor benefits from lower unit costs following the increased number of passengers at the remaining airports. Furthermore the total investments to fulfil the requirements in BSL E 3-2 will be reduced. Higher traffic will, generally, also increase Avinor's revenues from the network. Consequently, the company's economic performance will improve. Increased capacity utilization in a consolidated regional airport network enables the operation of an increased number of commercial routes, and also reduces the need for subsidised PSO-routes.

However, it is important to be aware that network restructuring may weaken the passenger basis for the current huband spoke system, and present passengers with a longer average transport distance to reach their local airport. The closure of regional airports could impose reduced transport standard for some passengers, due to increased travel costs getting to the airport, at least in the short run. This may especially be the case for passengers with high time costs living close to a discontinued airport. The reduced operating costs and costs for PSO-operations can be spent on further improvements in the road infrastructure in the region losing its airport and thereby raising the transport standard for both air transport passengers and other road users.

\footnotetext{
${ }^{4}$ Such a restructuring can for example be argued according to the extensive literature dating back to Coase's transaction cost theory [18] (theory of the firm).
}

\section{The Helgeland case}

The consequences of airport structure changes can be exemplified by the Helgeland region in the North of Norway. It is a politically stated goal to find a suitable location for a joint airport in this region [13]. The region is currently served by three airports, each with short runways $(<1,000 \mathrm{~m})$ and less than 100,000 passengers per year [9]. These airports are Mo i Rana (MQN) and Sandnessjøen (SSJ), opened in 1968, and Mosjøen (MJF), opened in 1987, see Fig. 1. None of these airports are situated in geographical areas with topography and weather conditions suitable for considerable runway expansion.

\subsection{Airport structure and air route services}

Flights from the airports are operated by PSO-routes provided by the same operator (Widerøes flyveselskap ASA) as at opening more than 40 years ago. The subsidy requirements for the route operations in the period 1st April 2009 to 31st March 2012 amount to about NOK 300 million ( $€ 37$ million). The air transport services are characterized by many stopovers (transit) and are operated by small aircrafts (39 seats).

Flight operations at these airports are often exposed to difficult wind and cloud conditions resulting in low reliability inflicting uncertainty and waiting costs on travellers. The uncertainty of the current flight programme probably explains why the population of this region only travelled 2.5 times to/ from the local airport on average in 2007 in relation to 7.3 at comparable airports. Air travel surveys show that almost 50\% of the passengers between the main airport in Oslo and this region chose to travel from the nearest large airport rather than the closest regional airport [13].

\subsection{Infrastructure improvements}

Since construction of these regional airports in 1968, the road infrastructure has been considerably improved in the region. ${ }^{5}$ Connections to the main roads have been improved and many towns which originally were hard to reach by private car are now interconnected by bridges and tunnels. Road infrastructure developments in the region from 1967 to 2009 are illustrated in Fig. 2.

In 1967, just one road connected the three towns. This road went from Sandnessjøen to Mosjøen using a ferry, and then on to Mo i Rana by road through a mountainous area. Four projects are indicated in Fig. 2 that, in addition to general road infrastructure improvements, have contributed

\footnotetext{
$\overline{5}$ Detailed sources for road infrastructure standards at different points in history are the periodical road description books published by the Norwegian Automobile Federation (NAF). In this case 1967 [21] forms the basis for studying the changes.
} 


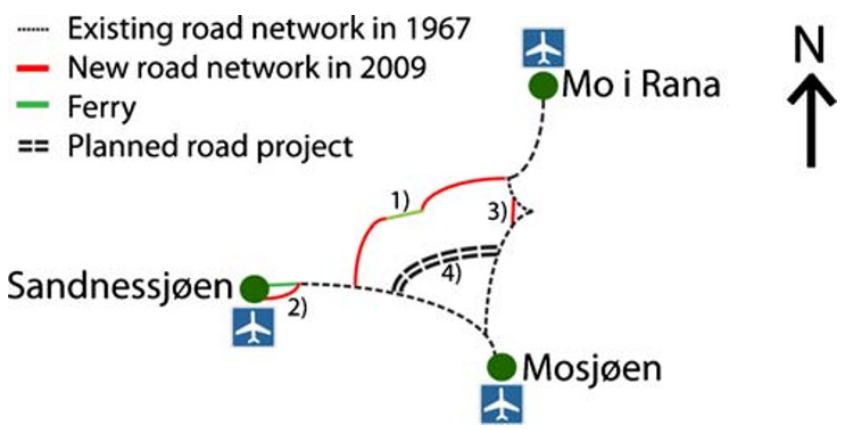

Fig. 2 Changes in the road network in the Helgeland region from 1967 to 2009

to better road accessibility between these three towns. First, a ferry crossing reducing the road distance for travellers from Sandnessjøen to Mo i Rana was established (marked as 1). Second, a bridge was constructed in 1991 eliminating the need for ferry transport for travellers from Sandnessjøen to the mainland (marked as 2). Third, a tunnel was built traversing a mountain area in 2005 , hereby removing a major bottleneck for road transport between the towns of Mosjøen and Mo i Rana (marked as 3). Finally, a tunnel is planned constructed which, when completed in 2013, will make a ferry crossing redundant and shorten time usage by road considerably [22].

Consequently, during the period from 1967 to 2009, increased road and vehicle standard has increased average vehicle speed. The relative time reduction varies from $31 \%$ to $36 \%$. The three towns of Mo i Rana, Mosjøen and Sandnessjøen will in 2013 all be mutually accessible by car within the space of $2 \mathrm{~h}$.

\subsection{The consequences of a joint airport}

The catchment area for a joint airport consists of about 65,000 inhabitants. Related to just one airport, as opposed to three, this population paves the way for more direct connections, lower average prices and commercial flights rather than PSO-routes to nearby large airports. Moreover, the airport owner Avinor will save a substantial amount on the investment budget through not having to upgrade the three current airports.

Cost benefit analyses (CBA) are designed to evaluate whether an alternative is better or worse than the base alternative (current status) from a welfare perspective by assessing change in consumer and producer surplus e.g. [23]. Recommendations for deriving economic benefits related to airport infrastructure projects in Norway are given by [24]. These benefits are discounted by an interest rate of $4.5 \%$ over a period of 25 years. In total, the welfare benefits derived from replacing the three airports in question with one joint airport amount to about NOK 4.9 billion [25]. Details of these benefits are presented in Table 1 and further elaborated on in the following sections emphasising assessments from a welfare economic perspective.

\subsubsection{Increased user benefits}

Both the business community and the population of the region will enjoy reductions in generalized travel costs for their trips to/from Oslo if a joint airport is constructed. When calculating change in generalized travel costs [13] find that reduced fares and shorter flight times more than compensate for the increased costs of driving to the airport for both business and leisure travellers. Net savings for users amount to NOK 2,900 million: adding the sum of NOK 1,600 million for work trips to NOK 1,300 million for leisure trips.

\subsubsection{No need for PSO-operations}

A larger catchment area, runways serving jet-planes and a simpler route structure (fewer airports to serve) are, in sum, expected to enable regular commercial flights thus removing the need for PSO-subsidies at the joint airport. Discontinuation of PSO-operations saves MTC from providing subsidies amounting to about NOK 100 million per year, corresponding to a discounted value of NOK 1,500 million. Revenues for air
Table 1 The economic benefits of a joint airport for Northern Helgeland (2009 prices)

\footnotetext{
${ }^{\text {a }}$ Values are estimated in accordance with the Norwegian recommendations for cost benefit analyses for air transport investments [24]
}

\begin{tabular}{|c|c|c|}
\hline Category & Million NOK $^{\mathrm{a}}$ & Comments \\
\hline User benefits & 2,900 & $\begin{array}{l}\text { Divided between } 1,600 \text { NOK for work trips } \\
\text { and } 1,300 \text { NOK for leisure trips. }\end{array}$ \\
\hline $\begin{array}{l}\text { Ministry of Transport and } \\
\text { Communication }\end{array}$ & 1,800 & $\begin{array}{l}\text { Reduced subsidies due to the need for fewer } \\
\text { PSO-routes, including } 20 \% \text { taxation effect. }\end{array}$ \\
\hline Accidents, noise and pollution & 50 & $\begin{array}{l}\text { Primarily due to reduced accidents (road), noise } \\
\text { (air) and pollution (air). }\end{array}$ \\
\hline Airline companies & -100 & Reduced profits in the airline industry. \\
\hline Avinor (airport owner) & 250 & Reduced operating costs. \\
\hline Total economic benefit & 4,900 & Sum net present value of benefits. \\
\hline
\end{tabular}


transport companies are reduced accordingly. However, a welfare economic assessment only includes the cost of raising public funds by taxation. This cost has been set by The Norwegian Ministry of Finance [26] to 20\% amounting to NOK 300 million.

\subsubsection{Changes in accidents, noise and pollution}

The change in airport structure will affect externalities such as the incidence of accidents, noise and pollution both for road transport and air transport services. The probability and consequences of flight accidents change due to new flight patterns and the use of larger planes. Using the framework for valuation of accidents, noise and pollution proposed by [24], the reduction in external costs is estimated to amount to about NOK 50 million.

\subsubsection{Influence on airline companies}

The number of routes in the region will be reduced on discontinuation of two airports. Fewer flights with higher capacity utilization will decrease both the operating costs and airport charges directly related to the number of departures. However, with an increase in competition and discontinuation of PSO-subsidies airline companies are expected to experience a reduction in profitability with a discounted value amounting to NOK 100 million.

\subsubsection{Impact on operating costs for airport owner}

The regional airports in the region had, in 2008, operating expenses amounting to NOK 75 million. Annual operating costs at the new joint airport are estimated to amount to about NOK 62 million. Hence, the annual reduction in operating costs is approximately NOK 13 million with a discounted value of NOK 200 million. Higher traffic figures will increase revenues by a discounted value amounting to about NOK 50 million. In sum, this will provide Avinor with a net gain of NOK 250 million. The airport will still be run with a deficit and will require cross-subsidisation from other profitable airports in the network.

\subsubsection{Profitability from a welfare perspective}

The changes in utility for the involved parts presented in Table 1 enable the calculation of the economic effect of the airport project from a welfare perspective. The total economic benefit of NOK 4.9 billion indicates the upper limit for construction costs, determining whether the project is profitable or not from a welfare perspective. The only suitable location for a larger airport is situated near Mo i Rana and involves estimated construction costs of about NOK 1,500 million. Hence, the profitability from a welfare perspective is about NOK 3.4 billion and derives a CBAfraction of more than 3 .

\subsection{Regional effects}

It is well-recognized that improved infrastructure in general, and airports in particular, brings about positive regional effects [2]. The extended effects of air transport are normally divided into direct, indirect, induced and catalytic effects e. g. [4]. Direct and indirect effects are related to the daily operation of the airport and the use of suppliers. Induced and catalytic effects are less tangible and brought about by the localisation of new businesses in the region due to the mere presence of an airport in the region. Even though direct and indirect effects may be considerable, the induced and catalytic effects still stand out as the most important with regard to the long-run development of the region in which the airport is located.

The main reasons for restructuring the airport network in the Helgeland region centre round realizing the potential positive effects related to trade and bettering competitive conditions for businesses. A new joint airport will offer considerable positive catalytic effects for the business community in general - and particularly the tourism and manufacturing industry. Direct flight connections to/from Oslo lower the barriers related to distance for establishing and maintaining contact with suppliers, customers and authorities. The international trend of higher travel frequency related to vacations with shorter duration revealed by travel studies e.g. [27] makes direct connections a critical success criterion for the tourism industry. It is reasonable to expect that these catalytic effects will be substantial if a direct connection to Oslo is established. The positive catalytic effects will stand out even more prominently if the road infrastructure is improved, providing better accessibility within the region.

\subsection{Alternative use of aviation subsidies}

In order to achieve local acceptance for fewer airports, it is often necessary to offer compensation to the municipalities losing their local airports. A feasible measure of compensation is to use cost savings in airport operations and PSOroutes to make extraordinary investments and maintenance in the road infrastructure in order to reduce passengers' distance costs. Such a way of financing infrastructure projects has been suggested in other parts of Norway.

The discounted value of reduced airport operating costs and the end of the need for PSO-operations are in sum estimated to amount to NOK 1,750 million. Parts of this amount could be spent for road infrastructure investments in the Helgeland region. There is, for example, a need to upgrade the European highway (E6) with an estimated cost 
of NOK 500 million [28]. Additional positive consequences of completing this road project accrue in the form of reduced transport and accident costs for users amounting to NOK 26 million and NOK 13 million, respectively.

\section{Conclusions and implications}

The Norwegian network of regional airports was established at the end of the 1960's and during the 1970's and has remained virtually unchanged since construction. Over the same four decades, travel time by car between cities holding regional airports has been considerably reduced due to infrastructure investment in roads, bridges, tunnels and ferry connections. A case in point is the Helgeland region in Norway where travel time by road between the three regional airports has been reduced by more than 30\% from 1967 to 2009.

During recent years operating costs for the regional airports have increased substantially, mainly due to the introduction of new specifications for safety and security at airports (regulation BSL E 3-2). Moreover, many regional airports require substantial investments being made in runways, safety zones, terminal buildings etc. in order to fulfil the requirements set out in the regulation. The subsidy requirements for the PSO-routes serving these airports have also shown a rapidly increasing curve, mainly for three reasons. First, there has been leakage of passengers to larger airports with lower ticket prices and better flight connections. Second, costs have increased for flight operations due to higher factor prices (fuel, pilots and flight attendants). Finally, there is virtually no competition for tendered PSO-contracts. Not surprisingly, in addition to running with a deficit, some of the regional airports are unprofitable according to general principles of economic welfare.

The regional airport structure in Norway is now overripe for reassessment. Closure of the most unprofitable airports from a welfare perspective combined with investments in some of the existing ones or construction of new airports could partially solve the main challenges. With regard to the Norwegian regional airports we would especially like to emphasise that:

- A reduction in the number of airports gives each remaining airport a larger catchment area enabling better flight connections; especially direct flights to/from the national main airport.

- Better flight connections stimulate demand and have a self-strengthening effect on travel frequency by reducing passengers' generalized travel costs.

- Fewer airports give the airport-owner Avinor reduced operating costs, thereby providing the financial platform to carry out necessary investments at the remaining airports.

- Through more efficient route operations and increased competition amongst airlines, more connections can be served on a commercial basis. This reduces the need for PSO-routes and corresponding subsidy requirements.

- Better flight connections in general, and lower ticket prices in particular, will have positive regional effects for local industry, commerce and tourism.

However, it is important to bear in mind that too strong a reduction of the number of airports may weaken parts of the present hub- and spoke system, and could therefore lead to reduced service at existing hubs. A reduction in the number of airports would also bring up the issue of compensatory measures in the form of investments in sections of the road system - so that passengers' travel costs to and from the airports are reduced. It is also important to consider how a change in the regional airport structure, the route network and the travel pattern will influence the environment. It should be ensured that structural changes do not conflict with Norway's environmental obligations.

Based on conclusions from the Norwegian aviation case, some of the knowledge hereby gleaned can be transferred to other countries where domestic air services play a central role in the public transport system:

- Authorities should consider investments in road transport infrastructure and aviation infrastructure in relation to one another, attempting to find an economic, futureoriented and sustainable distribution of trips between the various transport modes.

- Traditional cost-benefit analysis can provide useful information as to whether a given change in airport structure is economically profitable or not.

- It is important to visualize the distributional effects of different measures and also consider relevant compensating measures for groups or regions experiencing the disadvantages of airport structure changes.

If these general guidelines are followed, transport authorities can obtain objective and professional documentation concerning costs and benefits as a result of a particular measure. This will ensure that the risk for making decisions of an economically unprofitable nature is reduced. At the same time good documentation of the distributional effects and possible remedy measures compensating those who may suffer detrimental effects means that the local political discussions naturally following in the wake of larger infrastructure changes will hopefully become more objective and better founded. 
Open Access This article is distributed under the terms of the Creative Commons Attribution License which permits any use, distribution and reproduction in any medium, provided the original author(s) and source are credited.

\section{References}

1. Graham B, Guyer C (2000) The role of regional airports and air services in the United Kingdom. J Transp Geogr 8(4):249-262

2. ACI (2004) The social and economic impact of airports in Europe. York Aviation

3. Daley B (2009) Is air transport an effective tool for sustainable development? Sustain Dev 17(4):210-219

4. Cooper A, Smith P (2005) The Economic Catalytic Effects of Air Transport in Europe. Eurocontrol-Experimental Centre, Oxford

5. Williams G, Fewings R, Fuglum K (2007) Airport provision and air transport dependence in European countries. J Airpt Manag 1 (4):398-412

6. European Commission (2009) Public service obligations - list of routes concerned. Working document based on information from the Official Journal and on data delivered by Member States. http://ec.europa.eu/ transport/air/internal_market/doc/2009_11_03_pso_inventory.pdf. Accessed 11 January 2010

7. Williams G, Pagliari R (2004) A comparative analysis of the application and use of public service obligations in air transport within the EU. Transp Policy 11(1):55-66

8. Lian JI, Rønnevik J (2011) Airport competition-Regional airports losing ground to main airports. J Transp Geogr 19(1):85-92

9. Avinor (2011) Traffic statistics, http://www.avinor.no/en/avinor/ traffic

10. Lian JI (2010) Network dependency and airline competition Consequences for remote areas in Norway. J Air Transp Manag 16(3):137-143

11. Salvanes KG, Steen F, Sørgard L (2003) Collude, compete, or both? Deregulation in the Norwegian airline industry. J Transp Econ Policy 37:383-416

12. Ida N, Tamura T (2005) Effects of deregulation on local air passenger demand. Res Transp Econ 13:211-231

13. Hanssen T-ES, Mathisen TA (2011) Den regionale lufthavnstrukturen i Norge - Hvor mange lufthavner trenger vi? (In Norwegian)
Selected Proceedings from the Annual Transport Conference at Aalborg University, Trafikdage 2008, Aalborg, Denmark

14. EU (2008) Regulation no. 1008/2008 of 24 September 2008 on common rules for the operation of air services in the Community

15. Klemperer P (1999) Auction theory: a guide to the literature. J Econ Surv 13(3):227-286

16. The Norwegian Ministry of Transport and Communication (2006) FOR 2006-07-06 nr 968: forskrift om utforming av store flyplasser (BSL E 3-2). Oslo. (In Norwegian)

17. Phillips OR, Weatherford LR, Mason CF, Kunce M (2005) Passenger leaks and the fate of small community air service. Econ Inq 43(4):785-794

18. Coase R (1937) The nature of the firm. Economica 4(16):386-405

19. Martín JC, Voltes-Dorta A (2011) The econometric estimation of airports' cost function. Transport Res Part B: Methodol 45(1):112127

20. Motta M (2004) Competition policy: theory and practice. Cambridge University Press, Cambridge

21. Norwegian Automobile Federation (1967) Vegbok, Oslo. (In Norwegian)

22. The Norwegian Public Roads Administration (2006) Reguleringsplan. Rv. 78 Holand - Leirosen m/arm Drevja-Ømmervatn. (In Norwegian)

23. Jorge JD, de Rus G (2004) Cost-benefit analysis of investments in airport infrastructure: a practical approach. J Air Transp Manag 10 (5):311-326

24. Bråthen S, Eriksen K, Johansen S, Killi M, Lillebakk L, Lyche L, Sandvik E, Strand S, Thune-Larsen H (2006) Cost benefit analyses in the Norwegian aviation sector. Report 0606 a. Møre Research, Molde

25. Thune-Larsen H, Lian JI (2009) Helgeland lufthavn - market and economic feasibility. TØI-report 1014/2009. Institute of Transport Economics, Oslo

26. The Norwegian Ministry of Finance (2005) Veiledning i samfunnsøkonomiske analyser (Guide for welfare economic analyses). Oslo

27. Denstadli JM, Gripsrud M, Rideng A (2008) International and domestic air travel in Norway 2007. TØI-report 1028/2009. Institute of Transport Economics, Oslo

28. The Norwegian Public Roads Administration (2006) Rutevis utredning Stamvegrute 7. E6 Ranheim-Fauske med tilknytninger. (In Norwegian). Oslo 